\title{
GAS NITRIDING INFLUENCE ON FATIGUE AND CREEP BEHAVIORS IN TITANIUM GRADE 2
}

\author{
Palma, $\mathrm{KMS}^{1}$; Perina $\mathrm{GB}^{1}$; Velloso VMO${ }^{2}$; Baptista, CARP ${ }^{1}$; Barboza, $\mathrm{MJR}^{1}$ \\ ${ }^{1}$ Department of Materials, Escola de Engenharia de Lorena, University of São Paulo - USP, Brazil \\ 2 Department of Materials and Technology, Fatigue and Aeronautic Materials Research Group, Faculdade de Engenharia de \\ Guaratinguetá, São Paulo State University - UNESP, Brazil
}

\begin{abstract}
The present work aims nitriding to investigate the effect on titanium grade 2 with rotating bending fatigue tests at room temperature and short-term creep tests at $500^{\circ} \mathrm{C}$. The nitriding treatment was carried out at $850^{\circ} \mathrm{C}$ for 9 hours. After thermochemical treatment, XRD analysis revealed the formation layer composed of $\mathrm{TiN}^{\mathrm{N}} \mathrm{and} \mathrm{Ti}_{2} \mathrm{~N}$. Microscopy analysis revealed the presence of a uniform layer with a mean thickness of $3.6 \mathrm{mM}$ and $50 \%$ increase in surface roughness. Fatigue life $\left(10^{7} \mathrm{cycles}\right)$ was reduced by $42 \%$ by increasing surface roughness. On the other hand, nitriding treatment increased creep life by at least two times due to oxidation rate reducion and blocking dislocations movement by nitrogen in solid solution during the plastic deformation process.
\end{abstract}

\section{Introduction}

Titanium and its alloys are applied in the aerospace, biomedical and petrochemical industries, since they have high strength/weight ratio, good corrosion resistance and biocompatibility [1, 2].

Creep deformation mechanisms are typical in a system with high temperatures $\left(T>0.4 T_{f}\right)$ and constant load resulting in timedependent plastic deformation. The creep deformation of metals is developed in three stages involving microstructural changes, highly dependent on processing, volume fraction and morphology of the phases, and on the surface conditions. The literature reports that Ti$6 \mathrm{Al}-4 \mathrm{~V}$ alloy shows creep activity, in significant levels, at temperatures above $300^{\circ} \mathrm{C}$, governed by dislocation slipping and climbing [3-5].

The mechanisms and stages that failed a metal component due to fatigue are known. When subjected to cyclic loading, the microstructure of a metal component is modified with respect to dislocation distribution and interaction. The crack nucleation in a component, which occurs when the accommodation capacity of elastic deformation reaches its limit, occurs in regions of stress concentration. The fracture of the component is the result of a crack growth, perpendicular to the load application [6].

Surface treatments applied to titanium alloys, promotes resistance to erosion, oxidation and corrosion [7-9]. Previous studies about surface treatment influence on creep behavior of Ti-6Al-4V alloy showed that these treatments act on instantaneous deformation reduction and secondary deformation rate, increasing resistance to creep [10,11]. The results related with surface treatments applied on metal alloys subjected to fatigue are varied [12-15]. In general, the hard ceramic layers delay the crack nucleation and / or the deposition process modify the residual stress profile on the surface, generating compressive stresses and delaying crack propagation. On the other hand, the fatigue phenomenon is sensitive to surface finish and mechanical properties differences in coating/alloy interface [16-18]. Further studies are, therefore, needed to understand the different surface treatments influence on the mechanical behavior, under cyclic or constant loads, of an aeronautical and biomedical material, such as titanium grade 2 . Thus, this study aims to investigate the nitriding effect on rotating bending fatigue resistance at room temperature and on creep resistance, at $500^{\circ} \mathrm{C}$ of titanium grade 2 .

\section{Materials and methods}

(C) The Authors, published by EDP Sciences. This is an open access article distributed under the terms of the Creative Commons Attribution License 4.0 (http://creativecommons.org/licenses/by/4.0/). 
The material used in this study was titanium grade 2 with composition equal to 0.05 w.\% Fe, 0.03 w.\% C, 0.22 w.\% O, 0.03 w.\% $\mathrm{Ni}, 0.001 \mathrm{w} . \% \mathrm{H}$, and $99,669 \mathrm{w} . \%$ Ti. The thermochemical treatment was carried out in a furnace at $850{ }^{\circ} \mathrm{C}$ for nine (9) hours. The specimens were encapsulated in quartz tubes with pure nitrogen-rich atmosphere (99.99\%). Samples with (nitride) and without (asreceived) surface treatment were characterized by XRD, optical microscopy, profilometry and microhardness for the evaluation of the surface treatment effectiveness and surface compounds characterization. The fatigue tests were performed for all experimental conditions in rotating bending conditions $(R=-1)$, at room temperature, and conducted until rupture or $10^{7}$ cycles. The creep tests were conducted at $500^{\circ} \mathrm{C}$, the stress ranged between 55 and $100 \mathrm{MPa}$, in the as-received and nitride conditions. The creep rupture test was conducted based on ASTM 139-11 [19].

\section{$\underline{\text { Results }}$}

Figure 1 shows an optical micrograph of titanium grade 2 before surface treatment.

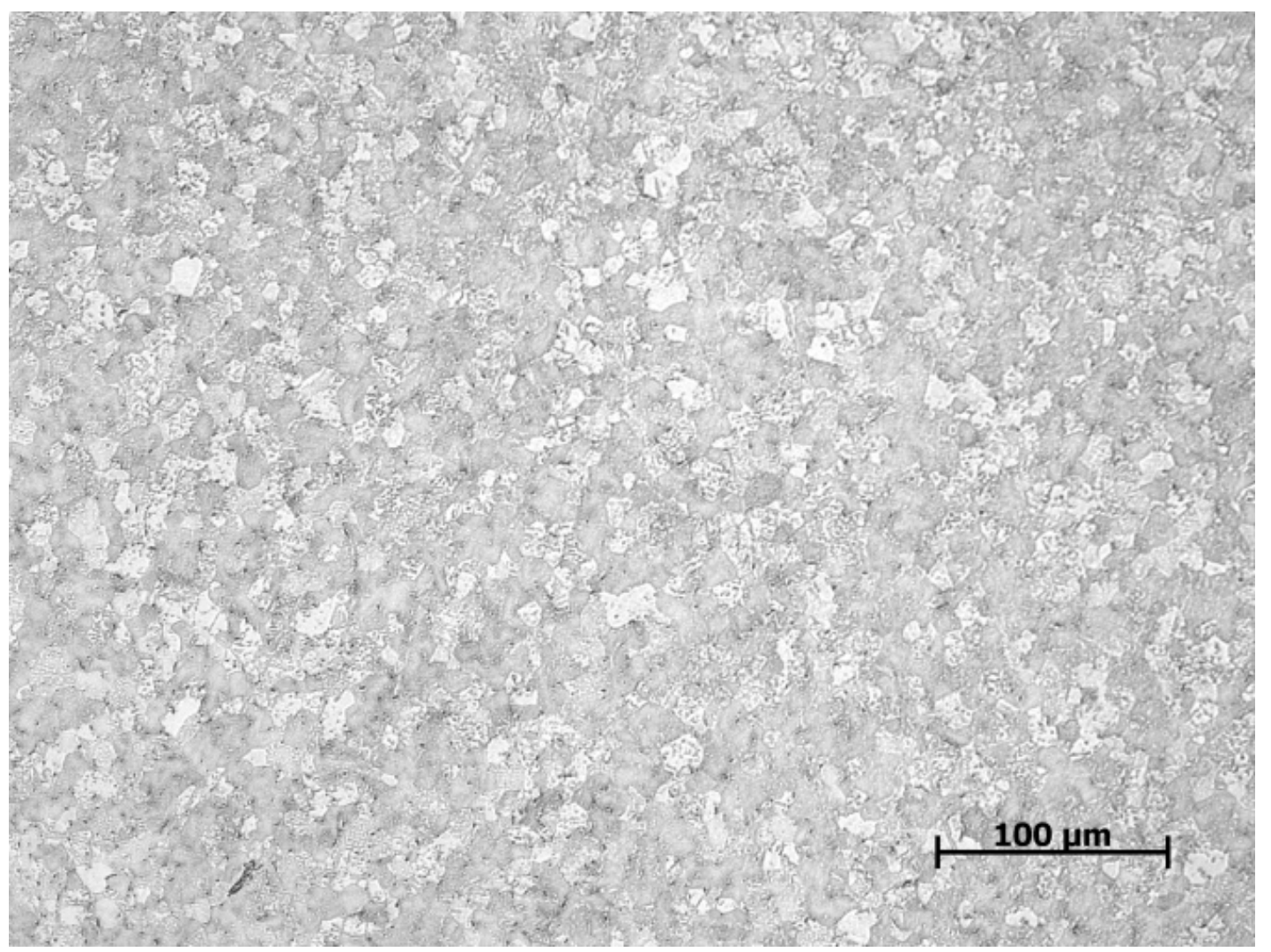

Figure 1. Optical microscopy of titanium grade 2 , cross section in the as-received condition.

Titanium grade 2 microstructure, in the as-received condition, has an average grain size of $12 \mu \mathrm{m}$ and a phase presence, which has hexagonal crystal structure and equiaxed morphology along the longitudinal and transverse sections. After thermochemical treatment, XRD analysis detected on the sample surface TiN phase with cubic structure, and the tetragonal structure phase, $\mathrm{Ti}_{2} \mathrm{~N}[20]$. Optical microscopy showed a uniform layer with average thickness equal to $3.6 \mu \mathrm{m}$. The mean values of surface microhardness of titanium grade 2 in as-received and nitrided conditions are shown in Table 1.

Table 1. Vickers microhardness of titanium grade 2 in the as-received and nitrided conditions.

\begin{tabular}{||l||c|}
\hline & Microhardness (HV) \\
\hline \hline as-received & $289 \pm 66$ \\
\hline \hline nitrided layer & $1125 \pm 82$ \\
\hline
\end{tabular}


The mean roughness of titanium grade 2 in the as-received and nitrided conditions are shown in Table 2.

Table 2. Average Roughness (Ra) of titanium grade 2 in the as-received and nitrided conditions.

\begin{tabular}{||l||c|}
\hline & Average Roughness Ra $(\mathrm{nm})$ \\
\hline as-received & $334 \pm 32$ \\
\hline nitrided layer & $536 \pm 22$ \\
\hline
\end{tabular}

Figure 2 shows the $\mathrm{S} \times \mathrm{N}$ curves for all experimental conditions.

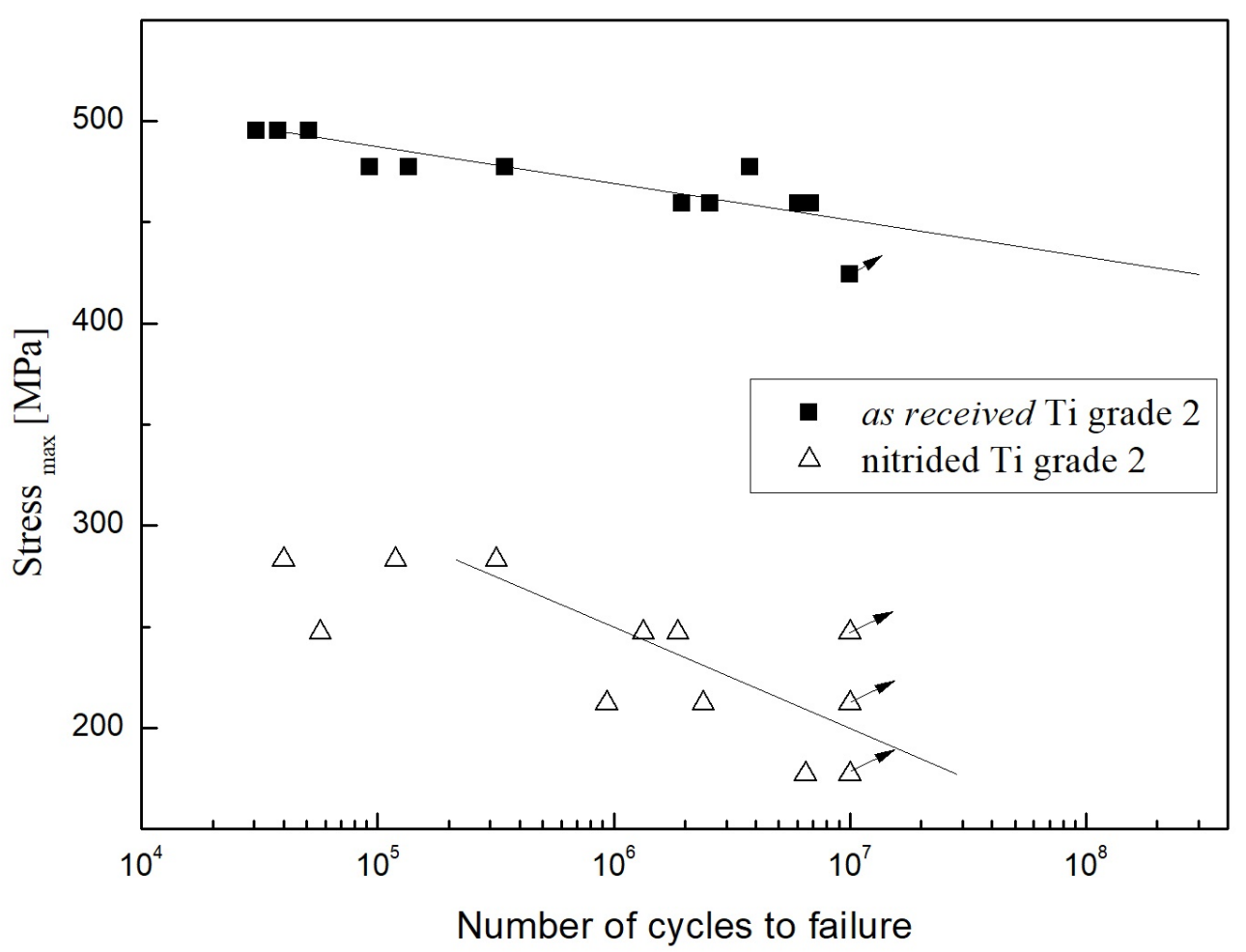

Figure 2. $\mathrm{S} \times \mathrm{N}$ curves of titanium grade 2 in the as-received and nitrided conditions with experimental data adjusted by maximum likelihood method.

Equations 1 and 2 simulated titanium grade 2 fatigue behavior according to the maximum likelihood model, where the runouts (censored test points by interruption reason) were incorporated into the results.

$$
\begin{aligned}
& \log N=31.8-(0.055 \times \sigma \max ) \\
& \log N=10.9-(0.02 \times \sigma \max )
\end{aligned}
$$


Based on Equations 1 and 2, for a lifetime of $10^{7}$ cycles, the nitriding treatment decreased the lifetime of titanium grade 2, in the as-received condition, during fatigue process in $42 \%$.

Table 3 shows the lifetime $\left(t_{f}\right)$ and final deformation $\left(\varepsilon_{f}\right)$ parameters obtained during the creep tests.

Table 3 Experimental parameters creep obtained at $500^{\circ} \mathrm{C}$ in the as-received and nitrided conditions.

\begin{tabular}{|c|c|c|c|c|c|c|}
\hline & Titanium grade 2 & & & Nitrided condition & & \\
\hline & $55 \mathrm{MPa}$ & $83 \mathrm{MPa}$ & $100 \mathrm{MPa}$ & $55 \mathrm{MPa}$ & $83 \mathrm{MPa}$ & $100 \mathrm{MPa}$ \\
\hline $\mathrm{t}_{\mathrm{f}}\left(10^{3 \mathrm{~s}}\right)$ & 409.7 & 43.8 & 16.7 & 824.1 & 99.9 & 37.8 \\
\hline$\varepsilon_{\mathrm{f}}(\mathrm{mm} / \mathrm{mm})$ & 0.61 & 0.82 & 0.87 & 0.88 & 0.68 & 0.58 \\
\hline
\end{tabular}

The relation between the absolute lifetime values of nitrided and as-received specimens $\left(\mathrm{t}_{\mathrm{fN}} / \mathrm{t}_{f} \mathrm{AR}_{\mathrm{R}}\right)$ shows that nitriding efficiency increases gradually with the applied stress. Thus, the lifetime for nitrided condition is, at least, twice higher than the one for as-received condition.

\section{Discussion}

Titanium and its alloys are known to exhibit heterogeneous behavior during plastic deformation. This behavior is related to its microstructure, which has few slip systems. The crack nucleation, on titanium surface during fatigue process, is related to dislocation slipping in prismatic and basal planes. However, the slipping activity is lower in the basal plane. Thus, the deformation is concentrated in the neighboring regions, imposing a higher strain level to the basal planes. In addition to external applied stress, the stress level on the basal plans exceeds the elastic limit and, therefore, cracks nucleate and spread more quickly along the basal planes [21] A ceramic layer should increase titanium resistance to fatigue, because the it has different deformation mechanisms, higher microhardness and consequently resistance to crack nucleation [22]. Farokhzadeh and Edrisy [23] have studied the fatigue behavior of Ti-6Al-4V alloy nitrided at $600^{\circ} \mathrm{C}$ for $24 \mathrm{~h}$. According to the authors, the treatment produced on surface a nitride layer with $2 \mu \mathrm{m}$ thickness, plus a nitrogen diffusion zone with $44 \mu \mathrm{m}$ of thickness. Fatigue life decreased due to the ceramic brittleness and surface roughness (4 times higher than the roughness of the untreated material) [23]. In this present work, the fatigue resistance decreasing was related to the nitride layer thickness and to the roughness increasing. The higher values of surface roughness increased the number of stress concentrator sites on surface, increasing the chances of crack nucleation. Once nucleated, the crack has no propagation resistance in coating due to its brittle nature [25]. Regarding creep behavior, the nitriding of titanium grade 2 decreased the surface oxidation effects, since nitrides have more stability at $500^{\circ} \mathrm{C}$, protecting the substrate reaction with the environment. Titanium reacts instantly with interstitial elements, proportional to the temperature increase [11]. At room temperature, titanium reacts with oxygen forming on surface a thin, uniform and adherent layer, $\mathrm{TiO}_{2}$ based. The increase in temperature decreases $\mathrm{TiO}_{2}$ stability, which grows in thickness and lose adhesion, exposing the substrate to atmosphere and lowering the support area strength [11, 25]. In this present study, the increase in creep resistance by nitriding treatment is related to the nitrates stability, which protect the substrate from the atmosphere, retarding the creep deformation mechanisms. The analysis of creep parameters indicates that creep deformation increasing with applied stress may be related to the increased movement of mobile dislocations in pure metal. For the nitrided condition, it is possible that at higher stress, nitrogen in solid solution restricted dislocation activity and reduced ductility.

\section{Conclusion}

This study examined the effects of nitriding on the creep and fatigue behaviors of titanium grade 2 . The main results are as follows: 
- The nitriding treatment reduced the fatigue life of titanium grade 2 due to increased surface roughness, which increases the number of stress concentrator sites on surface and to ceramic layer thickness, which has brittle nature;

- When subjected to creep, nitrided titanium demonstrated better resistance related to the nitride stability at $500^{\circ} \mathrm{C}$ and to the dislocation slipping restriction caused by nitrogen in solid solution;

- Studies of the interaction between fatigue and creep mechanisms of titanium grade 2 and their relationship with surface treatments can bring more information about titanium mechanical behavior subject to cyclical and constant loads and enable the application of the treated material in the aeronautics sector and biomedicine.

\section{Acknowledgments}

The authors would like to thank FAPESP (Proc. 2015/00331-2, 54987-0/2007), Conselho Nacional de Desenvolvimento Científico e Tecnológico (CNPq Proc. 151637/2015-6) and Coordenação de Aperfeiçoamento de Pessoal de Nível Superior - Brasil (CAPES - Finance Code 001), for the financial support.

\section{References}

[1] Boyer, R.R., Adv. Perform. Mater, 2 (1995) 349-368.

[2] Yonekura, D., Fujita J, Miki, K., Surf. Coat. Technol., 275 (2015) 232-238.

[3] Chang, L., Zhou, C., Peng, J., Li, J., He, X., 46 (2017) 1463-1468.

[4] Whittaker, M.T., Harrison, W.J., Lancaster, R.J., Williams, S. Mater Sci Eng A, 577 (2013) 114-119.

[5] Zherebtsov, S., Salishchev, G., Galeyev, A., Maekawa, K., 46 (2005) 2020-2025.

[6] Chan K,S,, Int J Fatigue 32 (2010) 1428-1447.

[7] Mahdipoor, M.S., Kevorkov D., Jedrzejowski P., Medraj M. Coatings Technol Surf; 292 (2016) 78-89.

[8] Péres, P., Surf Coatings Technol; 191 (2005) 293-302.

[9] Mohan G., Anandan C. Appl Surf Sci; 268 (2013) 288-296.

[10] Oliveira V.M.C.A., Smith M.C.L., Pinto C.G., Suzuki P.A., Machado, J.P.B., Chad, V.M., Barboza M.J.R. J Mater Res Technol, 4 (2015) 359-66.

[11] Oliveira V.M.C.A., Vazquez, A.M., Aguiar, C., Robin, A, Barboza M.J.R., Mater Sci Eng A, 670 (2016) 357-68.

[12] Yildiz F., Yetim, A.F., Alsaran, A., Celik, A., Kaymaz, I., Efeoğlu, I., Int Tribol; 66 (2013) 307-14.

[13] There N, Fulazzaky MA, Mustapa MS, Ghazali MI, Ridha M, Sujitno T. Int J Fatigue; 61 (2014) 184-90.

[14] Apachitei I L, Riemslag C, Apachitei LE. J. Appl Surf Sci ; 257 (2011) 6941-6944.

[15] Bonora, RG, Voorwald, HJC, Cioffi, MOH, Junior, GS, Santos, LFV. Eng Proceeding; 2 (2010) 1617-1623.

[16] Arias, D., Gomez, A., Jones, R.M., Velez, J.M. Physic and Chem Mater, 204 (2018) 269-276.

[17] Suh, C., Hwang, B., Murakami, A. Mater Sci Eng A, 343 (2003) 1-7. 
[18] Smolik, J., Garbacz H., Kurzyd, K.J., Wiecinski, P. Vacuum, 107 (2014) 277-283.

[19] ASTM E139-11(2018), ASTM International, West Conshohocken, PA, 2018.

[20] Zhecheva, S.W., Malinovs, S.A. Coat. Technol Surf; 200 (2005) 2192-2207.

[21] Bridier F, Villechaise P, Mendez J. Mater Acta, 53 (2005) 555-567.

[22] Tokaji K, Ogawa T, Shibata H. Japan Soc Trans Mech Eng; 57 (1999) 268-73.

[23] Farokhzadeh K, Edrisy A.Mater Sci Eng A; 620 (2015) 435-44.

[24] Oliveira VMCA, Cioffi MOH, Barbosa MJR, Landers R, Schmitt B, Tapia DCAR, Voorwald HJC. Int J Fatigue; 109 (2017) 157-65.

[25] Oliveira VMC, Aguiar C, Vazquez M, Robin A, Barboza MJR. Corrosion Sci; 88 (2014) 317-27. 